\title{
Peptide hormones and their prohormones
}

\section{as biomarkers}

\begin{abstract}
"...measurements of prohormone-derived fragments may be found to not be biomarkers in respect to their generic name, but may in fact represent new biological systems ... several new hormonally active peptides may be identified from already known prohormones in the future."
\end{abstract}

The accurate measurement of peptide hormones in plasma is a hallmark of basic and clinical endocrinology. From the discovery of the peptide secretin as the first bloodborne hormone to be recognized, the biological scenario for synthesis of peptide hormones now extends beyond endocrine glands to most types of tissues, including fat, muscle and nervous tissue. Accordingly, the use of hormonal peptides and their precursors as biomarkers involve several clinical disciplines besides endocrinology, where key differences in cellular synthesis and secretion must be considered in measurement and interpretation. Proper diagnostic use requires understanding of the biogenesis of hormones, including transcriptional, post-transcriptional, translational and post-translational processing and regulation of secretion. In this article, we address aspects regarding the plasma quantitation of peptide hormones and their biosynthetic precursors. It is worth noting that failure to appreciate the biosynthetic context of a peptide system can lead to mismeasurement and, at worst, fatal clinical errors.

Assay specificity is a key element in any standard validation. Although elementary, it has to be recapitulated that insufficient assessment of specificity is an issue of continuous concern. If the identification of a peptide as a biological entity is new, it may be difficult to test for specificity owing to the lack of relevant calibrator materials. Such a situation may lead researchers and diagnostic companies to document 'lack of unspecificity' by testing against more or less structurally related peptides. However, it is not the same thing. A troublesome example of lack of specificity has been reported for the measurement of $\mathrm{N}$-terminal pro-B-type natriuretic peptide (BNP), a sensitive marker of cardiac impairment, where comparison with a gold standard, in-house radioimmunoassay disclosed that a commercially available assay completely failed to detect the peptide in plasma [1] By contrast, assay specificity is a parameter that necessarily should not only detect one molecular form of a peptide hormone. An example is gastrin measurement for diagnosing gastrin-producing tumors (gastrinomas). In this malignancy, the biosynthetic apparatus is often able to mature only a small fraction of the prohormone to the normal end product (gastrin-17). Instead, gastrinomas secrete less processed fragments of progastrin. If the assay used for biochemical measurement is too specific for the normal physiological end product, gastrin-17, it will fail to detect some tumors, which is the major diagnostic indication for gastrin measurement $[2,3]$. Thus, specificity should be targeted with insight and reference to the molecular heterogeneity in health and during disease [4].

Another concern regarding plasma measurement is variable endoproteolytical cleavage(s) and amino acid derivatizations. These steps in the cellular synthesis are important, not only for the bioactivity and metabolism of peptides hormones, but they also affect immunological detection and biomarker use. In fact, some biomarkers utilize biological changes in cellular processing and, thereby, report on the stimulatory demand of the endocrine cells. A classic case is proinsulin measurement, where an increased demand on pancreatic $\beta$-cells leads to increased secretion of proinsulin [5]. As a result, measurement of the proinsulin:insulin ratio becomes an index of the total peripheral insulin resistance. For other peptide hormones, a molecular shift in the secreted forms towards processing intermediates or even intact precursors has also been observed [6]. An alternative strategy in assay measurement is bypassing the variable post-translational phase and quantifying one epitope that represents all translational products. This can be achieved by incubating plasma with an endoprotease (e.g., trypsin) in order to generate a uniform 'representative' fragment from the precursor as well as its biosynthetic products (Figure 1). The

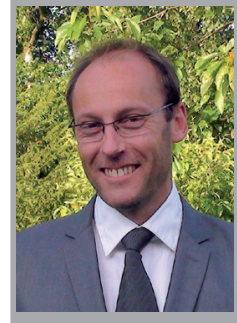

Jens P Goetze

Author for correspondence:

Department of Clinical

Biochemistry, Rigshospitalet,

University of Copenhagen,

9 Blegdamsvej, DK-2100,

Copenhagen, Denmark

Tel.: +45 3545 2202;

Fax: +45 3545 4640;

jpg@dadlnet.dk

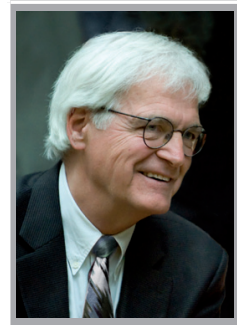

Jens F Rehfeld

Department of Clinical

Biochemistry, Rigshospitalet,

University of Copenhagen,

9 Blegdamsvej, DK-2100,

Copenhagen, Denmark 


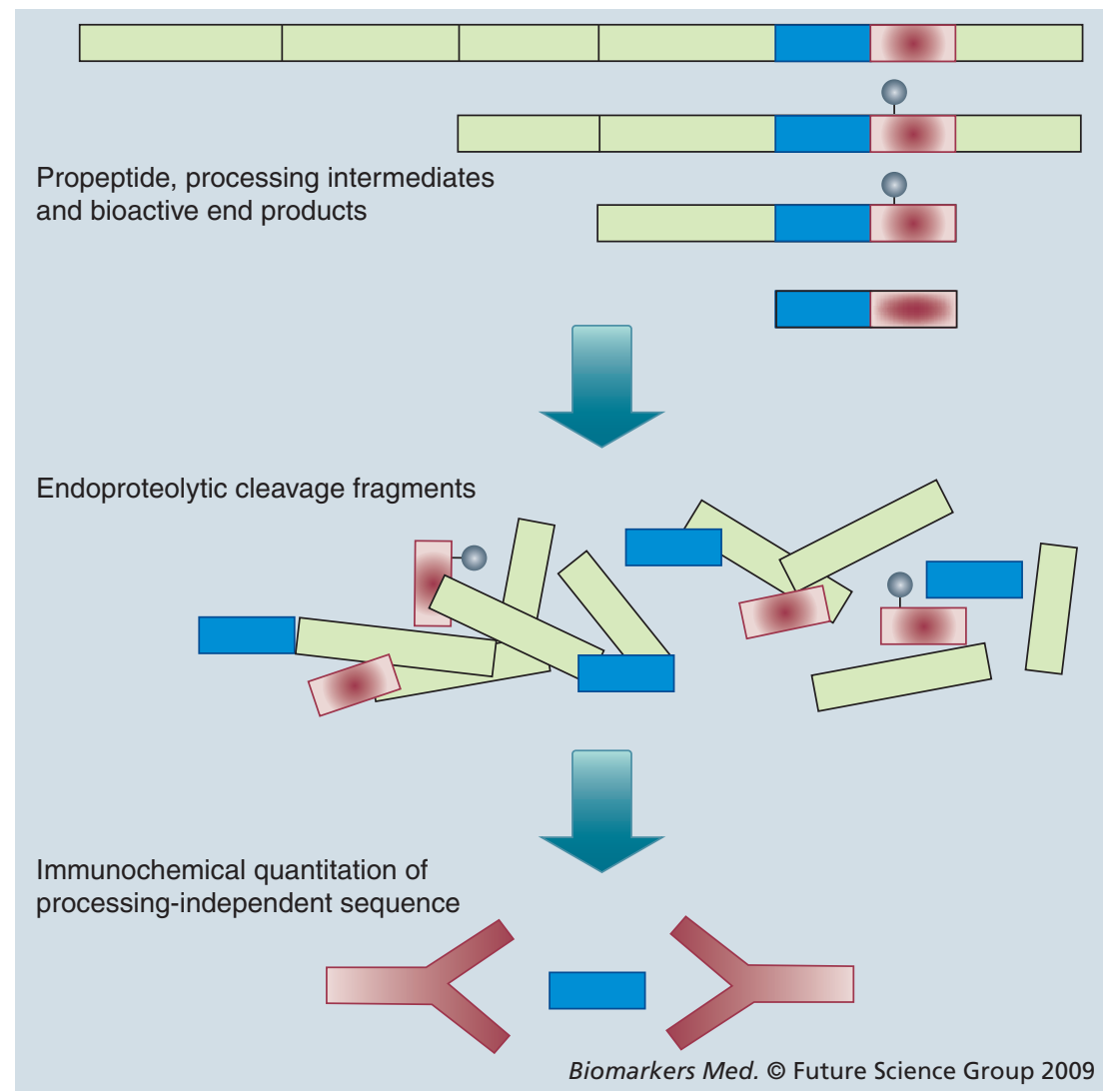

Figure 1. Principle in processing-independent analysis. Plasma is incubated with an endoprotease in order to produce a small peptide fragment. The fragment is then measured by standard immunoassays.

methodology also allows for assay calibration in the absence of larger synthetic or recombinant peptides. We have applied this principle in quantitation of several propeptides [7-9] and called it processing-independent assay (PIA) [7,10].

Many peptide hormones and their prohormones are subjected to amino acid derivatizations during biosynthesis. For instance, almost half of all peptide hormones undergo $\alpha$-carboxyamidation, which is often essential for their bioactivity [11]. The list of post-translational amino acid derivatizations is still growing (Tabie 1 ). At present, primary protein structures are deduced from cDNA sequences. Amino acid derivatizations, however, cannot be deduced. Mass spectrometry of peptides is required to determine the degree and nature of derivatizations. Moreover, it is likely that in the coming years, mass spectrometry will reveal new amino acid modifications along with the identification of the entire human proteome. The genes encoding many of the processing enzymes responsible for the amino acid derivatizations are now being cloned, and the enzyme structure and function are being identified. As several proprotein convertases may participate in the endoproteolytic processing of mono- and dibasic cleavage sites, a certain redundancy is also observed for enzymatic amino acid derivatizations. The exact role of each derivatization is not yet fully elucidated, where some appear to protect the peptide from enzymatic degradation both before and after cellular release. Other derivatizations increase or determine the interaction with binding proteins, such as chaperones, processing enzymes and receptors. Derivatizations may also serve as intracellular signals in the molecular trafficking $[12,13]$. Irrespective of the functional significance of a given derivatization, it influences measurement of the protein or peptide. The methods used for measurement are most often immunochemical, and if a given epitope on the protein or peptide contains one or more derivatizations, they may determine whether or to which extent the epitope is bound to antibodies. One example of this is the BNP precursor, which was recently shown to be glycosylated and that the degree of glycosylation affects endoproteolytic maturation $[13,14]$. O-linked pro-BNP glycosylation occurs at residues in the midregion, where immunoassays have utilized antibodies targeted at the primary structure in this domain [15]. It is worth noting that this modification was not known until recently, despite the fact that the gene was cloned 20 years ago. If the degree of modification is well characterized, however, this could in itself be used as a biomarker if assays are targeted at precisely these epitopes. This strategy deserves to be further pursued in diagnostic practice.

Table 1. Post-translational modifications.

\begin{tabular}{|lll|}
\hline Endoproteolytic cleavages & Exoproteolytic trimmings & Amino acid derivatizations \\
\hline Dibasic sites & Carboxyamidation & Acylation \\
\hline Monobasic sites & Glutaminyl cyclation & Disulfide bridging \\
\hline Post-(poly) Glu/Asp sites & N-terminal dipeptidyl cleavage & $\gamma$-carboxylation \\
\hline Post-Phe-sites & & Glycosylation \\
Tri- and tetrabasic sites & Isomerization \\
& Phosphorylation \\
& Sulfation \\
& Octanoylation \\
\hline
\end{tabular}


Taking the aforementioned aspects into account regarding the plasma measurement of peptide hormones and their precursors, it should be clear that establishing the true concentrations in plasma is often a cumbersome process. Discrepancies in concentrations between different assays are a common problem in laboratory diagnostics. Frequently, a peptide hormone is first measured in relatively high concentrations. Over time, however, accumulating information on hormone biogenesis and metabolism help assay development and, thereby, accurate measurement in plasma. A fine example in this regard is plasma measurement of cholecystokinin (CCK), a hormone secreted from the proximal gut to regulate gallbladder contraction and pancreatic enzyme secretion after a meal. The first assays reported CCK concentrations in the nanomolar range, but continuous efforts in elucidating the molecular heterogeneity and excluding interference has now established that CCK circulates in very low picomolar concentrations, under tight physiological control (Taвle 2). Thus, reported plasma concentrations may be subject to dramatic changes, as basic research unravels the molecular pitfalls and possibilities for assay development [16].

Measurement of peptide fragments other than the bioactive end product from a prohormone can have several advantages. A simple consideration is that the bioactive end product often has a short half-life in circulation and, thus, fluctuates too much to be used for diagnostic purposes. By contrast, processing-intermediate fragments may circulate in higher and more constant concentrations owing to slower metabolism. The C-peptide from proinsulin is probably the most used prohormone fragment in this regard and, similarly, $\mathrm{N}$-terminal fragments of the cardiac natriuretic peptide prohormones are likely to be useful biomarkers. One particular aspect should be emphasised in this respect, although we often use such measurement as a surrogate marker for gene expression, several prohormones have been shown to contain more than one bioactive peptide fragment with distinct physiological properties [17-20]. Thus, measurements of prohormone-derived fragments may be found not to be biomarkers in respect to their generic name, but may in fact represent new biological systems. We suspect that several new hormonally active peptides may be identified from already known prohormones in the future.

Measurement of peptide hormones and their prohormones is a diagnostic field that will expand over the coming decades. From being a hallmark of endocrinology, focusing on specialized endocrine glands, most tissues have now been shown
Table 2. Cholecystokinin concentrations in normal human plasma.

\begin{tabular}{|c|c|c|c|}
\hline \multirow[t]{2}{*}{ Assay epitope } & \multicolumn{2}{|c|}{ Plasma concentrations (pmol/l) } & \multirow{2}{*}{$\begin{array}{l}\text { Year of } \\
\text { publication }\end{array}$} \\
\hline & Basal & Maximal & \\
\hline Unknown & $<960$ & 77,000 & 1969 \\
\hline Unknown & 7 & 2000 & 1973 \\
\hline N-terminus of CCK-33 & 1220 & 2330 & 1973 \\
\hline $\mathrm{N}$-terminus of CCK-33 & 186 & 293 & 1975 \\
\hline Unknown & 97 & 123 & 1977 \\
\hline Unknown & 2400 & 4300 & 1978 \\
\hline C-terminus of CCK-33 & 8 & 24 & 1981 \\
\hline C-terminus of CCK-33 & 27 & 51 & 1982 \\
\hline Subtraction assay & $<0.8$ & 2 & 1982 \\
\hline Subtraction assay & $<0.2$ & 1 & 1982 \\
\hline C-terminus of CCK-33 & 11 & 25 & 1982 \\
\hline C-terminus of CCK-33 & $<6$ & 30 & 1982 \\
\hline Unknown & 5 & 12 & 1983 \\
\hline C-terminus of CCK-33 & 3 & 9 & 1983 \\
\hline Midregion of CCK-33 & 3 & 10 & 1983 \\
\hline C-terminus of CCK-33 & 16 & 28 & 1983 \\
\hline C-terminus of CCK-33 & 15 & 22 & 1984 \\
\hline C-terminus of CCK-33 & 6 & 23 & 1984 \\
\hline C-terminus of CCK-33 & 3 & 10 & 1985 \\
\hline C-terminus of CCK-33 & 1 & 7 & 1985 \\
\hline Subtraction assay & 14 & - & 1985 \\
\hline C-terminus of CCK-33 & 2 & 7 & 1986 \\
\hline C-terminus of CCK-33 & 2 & 27 & 1987 \\
\hline CCK-8 & 11 & 41 & 1988 \\
\hline CCK-8 & 1 & 3 & 1991 \\
\hline C-terminus of CCK-33 & 2 & 7 & 1992 \\
\hline C-terminus of CCK-33 & 1 & 5 & 1992 \\
\hline C-terminus of CCK-33 & 1 & 4 & 1993 \\
\hline CCK-8 & 0.5 & - & 1995 \\
\hline $\mathrm{N}$-terminus of CCK-22 & 1 & 2 & 1995 \\
\hline C-terminus of CCK-12 & 1 & 5 & 1998 \\
\hline
\end{tabular}

to produce and secrete hormonally active peptides that demonstrate substantial promise as biomarkers. Consequently, it will be necessary to keep focus on the elucidation of peptide biogenesis, secretion and metabolism, which should complement the diagnostic possibilities.

\section{Financial \& competing interests disclosure}

The authors have no relevant affiliations or financial involvement with any organization or entity with a financial interest in or financial conflict with the subject matter or materials discussed in the manuscript. This includes employment, consultancies, honoraria, stock ownership or options, expert testimony, grants or patents received or pending, or royalties.

No writing assistance was utilized in the production of this manuscript. 


\section{Bibliography}

1 Yandle T, Fisher S, Espiner E, Richards M, Nicholls G: Validating aminoterminal BNP assays: a word of caution. Lancet 353 , 1068-1069 (1999).

2 Goetze JP, Rehfeld JF: Impact of assay epitope specificity in gastrinoma diagnosis. Clin. Chem. 49, 333-334 (2003).

3 Goetze JP, Paloheimo LI, Linnala A, Sipponen P, Hansen CP, Rehfeld JF: Gastrin-17 specific antibodies are too specific for gastrinoma diagnosis but stain G-cells. Scand. J. Gastroenterol. 40, 596-598 (2005).

4 Rehfeld JF: The art of measuring gastrin in plasma: a dwindling diagnostic discipline? Scand. J. Clin. Lab. Invest. 68, 353-361 (2008).

5 Melani F, Rubenstein AH, Oyer PE, Steiner DF: Identification of proinsulin and C-peptide in human serum by a specific immunoassay. Proc. Natl Acad. Sci. USA 67, 148-155 (1970).

6 Giuliani I, Rieunier F, Larue C et al: Assay for measurement of intact B-type natriuretic peptide prohormone in blood. Clin. Chem. 52, 1054-1061 (2006).
7 Bardram L, Rehfeld JF: Processingindependent radioimmunoanalysis: a general analytical principle applied to progastrin and its products. Anal. Biochem. 175, 537-543 (1988).

8 Paloheimo LI, Rehfeld JF: A processingindependent assay for human procholecystokinin and its products. Clin. Chim. Acta 229, 49-65 (1994).

9 Goetze JP, Kastrup J, Pedersen F, Rehfeld JF: Quantification of pro-B-type natriuretic peptide and its products in human plasma by use of an analysis independent of precursor processing. Clin. Chem. 48, 1035-1042 (2002).

10 Rehfeld JF, Goetze JP: The posttranslational phase of gene expression: new possibilities in molecular diagnosis. Curr. Mol. Med. 3, 25-38 (2003).

11 Eipper BA, Mains RE: Peptide $\alpha$-amidation. Annu. Rev. Physiol. 50, 333-344 (1988).

12 Bundgaard JR, Vuust J, Rehfeld JF: Tyrosine $O$-sulfation promotes proteolytic processing of progastrin. EMBO J. 14, 3073-3079 (1995).

13 Semenov AG, Postnikov AB, Tamm NN et al:: Processing of pro-brain natriuretic peptide is suppressed by $O$-glycosylation in the region close to the cleavage site. Clin. Chem. 55, 489-498 (2009).
14 Schellenberger U, O'Rear J, Guzzetta A, Jue RA, Protter AA, Pollitt NS: The precursor to $\mathrm{B}$-type natriuretic peptide is an $O$-linked glycoprotein. Arch. Biochem. Biophys. 451, 160-166 (2006).

15 Goetze JP, Dahlström U, Rehfeld JF, Alehagen $U$ : Impact of epitope specificity and precursor maturation in pro-B-type natriuretic peptide measurement. Clin. Chem. 54, 1780-1787 (2008).

16 Rehfeld JF: How to measure cholecystokinin in tissue, plasma and cerebrospinal fluid. Regul. Pept. 78(1-3), 31-39 (1998).

17 Kobayashi H, Yanagita T, Yokoo H, Wada A: Pathophysiological function of adrenomedullin and proadrenomedullin $\mathrm{N}$-terminal peptides in adrenal chromaffin cells. Hypertens. Res. 26, S71-S78 (2003).

18 Steiner DF: The proinsulin C-peptide a multirole model. Exp. Diabesity Res. 5, 7-14 (2004).

19 Holst JJ: The physiology of glucagon-like peptide 1. Physiol. Rev. 87, 1409-1439 (2007).

20 Pemberton CJ, Richards AM: Biochemistry of ghrelin precursor peptides. Vitam. Horm. 77, 13-30 (2008). 